Article

\title{
Gene Analysis of Listeria monocytogenes Suspended Aggregates Induced by Ralstonia insidiosa Cell-Free Supernatants under Nutrient-Poor Environments
}

\author{
Qun Li ${ }^{1}$, Ailing Guo ${ }^{1, *} \mathbb{D}$, Yi Ma ${ }^{2, *}$, Ling Liu ${ }^{1}$, Wukang Liu ${ }^{1} \mathbb{D}$, Yuan Zhong ${ }^{1}$ and Yawen Zhang ${ }^{1}$ \\ 1 National Research and Development Center for Egg Processing, College of Food Science and Technology, \\ Huazhong Agriculture University, Wuhan 430070, China; liqun0617@126.com (Q.L.); \\ 18438605237@163.com (L.L.); liu_wukang@126.com (W.L.); zhongyuan2329@126.com (Y.Z.); \\ zywwwww1998@126.com (Y.Z.) \\ 2 Hubei Provincial Institute for Food Supervision and Test, Wuhan 430070, China \\ * Correspondence: ailingguo234@163.com (A.G.); mayi8370@163.com (Y.M.); Tel.: +86-1534-224-1896 (A.G.); \\ +86-1300-614-1812 (Y.M.)
}

check for updates

Citation: Li, Q.; Guo, A.; Ma, Y.; Liu, L.; Liu, W.; Zhong, Y.; Zhang, Y. Gene Analysis of Listeria monocytogenes Suspended Aggregates Induced by Ralstonia insidiosa Cell-Free Supernatants under Nutrient-Poor Environments. Microorganisms 2021, 9 , 2591. https://doi.org/10.3390/ microorganisms 9122591

Academic Editor: Edward Fox

Received: 23 November 2021 Accepted: 14 December 2021 Published: 15 December 2021

Publisher's Note: MDPI stays neutral with regard to jurisdictional claims in published maps and institutional affiliations.

Copyright: (C) 2021 by the authors. Licensee MDPI, Basel, Switzerland. This article is an open access article distributed under the terms and conditions of the Creative Commons Attribution (CC BY) license (https:/ / creativecommons.org/licenses/by/ $4.0 /)$.

\begin{abstract}
Listeria monocytogenes is a zoonotic food-borne pathogen. The production of food-borne pathogenic bacteria aggregates is considered to be a way to improve their resistance and persistence in the food chain. Ralstonia insidiosa has been shown to induce L. monocytogenes to form suspended aggregates, but induction mechanisms remain unclear. In the study, the effect of $R$. insidiosa cellfree supernatants cultured in 10\% TSB medium (10\% RIS) on the formation of L. monocytogenes suspended aggregates was evaluated. Next, the Illumina RNA sequencing was used to compare the transcriptional profiles of L. monocytogenes in 10\% TSB medium with and without $10 \%$ RIS to identify differentially expressed genes (DEGs). The result of functional annotation analysis of DEGs indicated that these genes mainly participate in two component system, bacterial chemotaxis and flagellar assembly. Then the reaction network of L. monocytogenes suspended aggregates with the presence of $10 \%$ RIS was summarized. The gene-deletion strain of L. monocytogenes was constructed by homologous recombination. The result showed that che A and che $Y$ are key genes in the formation of suspended aggregates. This research is the preliminary verification of suspended aggregates' RNA sequencing and is helpful to analyze the aggregation mechanisms of food-borne pathogenic bacteria from a new perspective.
\end{abstract}

Keywords: Listeria monocytogenes; Ralstonia insidiosa cell-free supernatants cultured in 10\% TSB medium; suspended aggregates; RNA-seq; formation mechanism; cheAY

\section{Introduction}

Listeria monocytogenes is a food-borne pathogen that is liable for a disease called listeriosis, a rare but severe disease in humans, who can become infected by ingesting contaminated food products. As a motile Gram-positive rod, L. monocytogenes can grow at a wide range of temperatures $\left(1\right.$ to $\left.45^{\circ} \mathrm{C}\right)$ and survives extreme growth conditions comparatively well, from $\mathrm{pH} 4.5$ to 9 and into $10 \% \mathrm{NaCl}$, but optimum growth occurs at $0.5 \% \mathrm{NaCl}$ and neutral $\mathrm{pH}$ [1]. Based on the characteristics of tolerance to high salt, low temperature and poor nutrition, L. monocytogenes is present widely in the environment, as it can be isolated from water, soil, silage, vegetables and food-processing environments [2]. In Denmark in 2016, two confirmed incidents of foodborne infection with L. monocytogenes were reported [3]. In 2019, an incident with contaminated chilled meat caused 1060 illnesses and 216 deaths [4]. According to the data on the number of biohazards in foods reported or recalled globally from 2008 to 2018, the number of hazards of L. monocytogenes surpassed Salmonella and Escherichia coli and ranked first, with a total of 387 cases [5]. Therefore, the presence of L. monocytogenes in food-processing environments is a major burden on the food industry and a challenge to food safety. 
Ralstonia insidiosa was first isolated by Coenye et al. in the United States in 2003; it belongs to non-fermenting, Gram-negative and aerobic bacteria and occasionally causes infection as an opportunistic pathogen [6]. R. insidiosa inhabits a broad range of the water environment, such as industrial pure water, laboratory pure water, river, pond and soil [7]. It has been shown that $R$. insidiosa is a link for the biofilm formation of L. monocytogenes, Salmonella enterica and E. coli [8]. Currently, there are few studies and reports on $R$. insidiosa.

Microorganisms are not insular entities, but they usually grow together in multispecies biofilm communities with complex classification [9]. The comparison between aggregation (i.e., adhesion in aquatic environments without a surface) and biofilm formation (i.e., adhesion to the surface) is presently unclear. Moreover, they may be related to the surface where microorganisms live, and aggregation is one of the processes of biofilm formation [10]. In the natural liquid environment, bacterial cells usually combine with the wet surface and interface in the shape of multicellular aggregates, some of which are called suspended aggregates [11]. Suspended aggregates are regarded as non-classical biofilms, in which microbial cells strongly express extracellular polymeric substances (EPS) components but do not directly contact the surface [12,13]. Some bacteria can form flocs through the aggregation process with the help of other bacteria [14]. The non-aggregating bacterium Xenophilus was also discovered to aggregate, but only with the assistance of Methylobacterium [10]. Methylobacterium may act as a bridging microorganism in cross species aggregate formation. In 2018, Trunk et al. found that the auto-aggregation or adhesion of the same bacteria to each other not only depends on environmental conditions, but also on different bacterial species [15]. However, L. monocytogenes can be induced to form suspended aggregates by $R$. insidiosa but cannot form suspended aggregates by itself [16]. In these well-organized structures, microorganisms may be free from environmental pressure, such as disinfectants and cleaning, and ecological interactions may occur among different species [17]. It is currently reported that suspended aggregates are the root cause of chronic diseases [18,19], and suspended aggregates have attracted more and more attention.

The production of suspended aggregates may be caused by the production of secondary metabolites by these bacteria to promote the formation of suspended aggregates [20]. Based on the research of Guo et al. [16], we evaluated the effect of $R$. insidiosa cell-free supernatants cultured in 10\% TSB medium (10\% RIS) on the formation of suspended aggregates formed by L. monocytogenes. RNA sequencing (RNA-seq) can be applied to determine the transcriptional changes in the interactions between pathogenic bacteria and microbial interspecies [21]. Then RNA-seq was utilized for preliminarily analyzing the impact of the formation of L. monocytogenes suspended aggregates induced by $10 \%$ RIS on the transcriptome of L. monocytogenes. This study can explain the factors affecting the formation of suspended aggregates by L. monocytogenes in terms of the genetic level, and bring new ideas for the prevention and control of food-borne pathogens in food processing environments. Investigating L. monocytogenes aggregation may provide insight into how the bacterium successfully transitions between its different niches, as well as reveal general mechanisms underlying non-surface-dependent multicellular community formation.

\section{Materials and Methods}

\subsection{Bacterial Strains and Growth Media}

The L. monocytogenes isolate used, with designated strain name "100", was previously isolated from a milk sample. Previous experiments in our laboratory identified this as a serotype $1 / 2$ a strain with strong biofilm and suspended aggregate formation ability. $R$. insidiosa ATCC 49129 was purchased from the American Type Culture Collection (ATCC). Both strains were stored at $-80^{\circ} \mathrm{C}$ in tryptic soy broth (TSB; Hope Bio-Technology, Qingdao, China) containing $40 \%$ glycerol. Before all experiments, frozen cells were activated and separated on tryptic soy agar plates (TSA; Hope Bio-Technology, Qingdao, China) for $24 \mathrm{~h}$ at $37^{\circ} \mathrm{C}$. Then one colony was transferred into TSB overnight at $37^{\circ} \mathrm{C}$, and the cell concentration was adjusted to $10^{8}$ colony-forming units (CFU)/mL. The concentration of 
bacteria used in each experiment was $10^{8} \mathrm{CFU} / \mathrm{mL}$, unless otherwise specified. E. coli $\mathrm{DH} 5 \alpha$ (Takara Bio Inc., Otsu, Shiga, Japan) was used as the standard plasmid host for cloning procedures and was grown in lysogeny broth (LB; Hope Bio-Technology, Qingdao, China) broth and agar. Ampicillin $(100 \mu \mathrm{g} / \mathrm{mL}$ ) (Biofroxx, Einhausen, Germany) or erythromycin $(3 \mu \mathrm{g} / \mathrm{mL})$ (Solarbio, Beijing, China) were added to agar media or broth as required.

\subsection{Preparation of Suspended Aggregates}

\subsubsection{Suspended Aggregate Formation of L. Monocytogenes}

As previously described [16], $200 \mu \mathrm{L}$ of L. monocytogenes was cultured into the $90 \mathrm{~mm}$ plastic Petri dish containing $20 \mathrm{~mL} \mathrm{10 \%} \mathrm{TSB} \mathrm{medium.} \mathrm{Thereafter,} \mathrm{the} 90 \mathrm{~mm}$ plastic Petri dish was cultured at $28{ }^{\circ} \mathrm{C}$ and $60 \mathrm{RPM}$. The formation of suspended aggregates was checked, compared and photographed daily.

\subsubsection{Suspended Aggregate Formation of L. Monocytogenes Induced by $10 \%$ RIS}

The R. insidiosa colony was transferred into $10 \%$ TSB medium for $24 \mathrm{~h}$ at $28{ }^{\circ} \mathrm{C}$ and $150 \mathrm{RPM}$. The culture fluid was centrifuged for $15 \mathrm{~min}$ at 10,000 RPM. The cell supernatant was filtered with a $0.22 \mu \mathrm{m}$ cell filter. The supernatant after filtration was cultured by TSA plates and TSB medium to ensure the sterilization effect. A total of $200 \mu \mathrm{L}$ of the $L$. monocytogenes was cultured into a $90 \mathrm{~mm}$ plastic Petri dish with $10 \mathrm{~mL} 10 \%$ RIS and $10 \mathrm{~mL}$ $10 \%$ TSB medium. Thereafter, the $90 \mathrm{~mm}$ Petri dish was cultured at $28^{\circ} \mathrm{C}$ with $60 \mathrm{RPM}$. The formation of suspended aggregates was checked, compared and photographed daily.

\subsection{Scanning Electron Microscopic Observation of Suspended Aggregates}

According to the methods in Sections 2.2.1 and 2.2.2, the suspended aggregates formed after $24 \mathrm{~h}$ were collected. After 5 min of centrifugation at $4000 \mathrm{RPM}$, the supernatant was removed, and the precipitate was cleaned with a physiological saline solution. The precipitate was fixed with phosphate buffer solutions of $2.5 \%$ ( $\mathrm{vol} / \mathrm{vol}$ ) glutaraldehyde $(\mathrm{pH} 7.4,0.02 \mathrm{M})$ and placed in a refrigerator at $4{ }^{\circ} \mathrm{C}$. After $12 \mathrm{~h}$, the aggregates were centrifugated at $4000 \mathrm{RPM}$ for $10 \mathrm{~min}$ and cleaned with $0.02 \mathrm{M}$ phosphate buffered saline ( $\mathrm{pH}$ 7.4) for 3 times. Then the obtained precipitate was washed with gradient concentration of $30 \%, 50 \%, 70 \%$ and $90 \%$ (vol/vol) ethanol successively for $10 \mathrm{~min}$ each time. The next step was to treat twice with $100 \%$ ethanol and remove the ethanol by centrifugation. The bacterial pellet was resuspended twice in $100 \%$ tert-butanol for two times and stored up in a refrigerator at $4{ }^{\circ} \mathrm{C}$ for $30 \mathrm{~min}$; they were then resuspended in $100 \%$ tert-butanol for vacuum freeze-drying for $48 \mathrm{~h}$. the dried powder samples were placed under a scanning electron microscope (JSM-6390LV, JEOL, Tokyo, Japan) for observation.

\subsection{Preparation of Sequencing Samples}

\subsubsection{Monocytogenes Sample}

A total of $200 \mu \mathrm{L}$ of the L. monocytogenes was cultured into a $90 \mathrm{~mm}$ plastic Petri dish with $20 \mathrm{~mL} 10 \%$ TSB medium. Then the $90 \mathrm{~mm}$ plastic Petri dish was cultured at $28^{\circ} \mathrm{C}$ and $60 \mathrm{RPM}$ for $24 \mathrm{~h}$. After $20 \mathrm{~min}$ of centrifugation at $5000 \mathrm{RPM}$, the cell supernatant was removed, and then the bacterial pellet was washed twice by physiological saline solution. The sample number was $X$. Three biological replicate experiments were performed for each group of samples.

\subsubsection{Suspended Aggregate Sample}

A total of $200 \mu \mathrm{L}$ of the L. monocytogenes was cultured into a $90 \mathrm{~mm}$ plastic Petri dish with $10 \mathrm{~mL} \mathrm{10 \%} \mathrm{RIS} \mathrm{and} 10 \mathrm{~mL} 10 \%$ TSB medium. Thereafter, the $90 \mathrm{~mm}$ plastic Petri dish was cultured at $28^{\circ} \mathrm{C}$ and $60 \mathrm{RPM}$ for $24 \mathrm{~h}$. The suspended aggregates were washed twice by physiological saline solution. The sample number was Y. Three biological replicate experiments were performed for each group of samples. 


\subsection{Extraction and Purification of RNA from Suspended Aggregates or L. monocytogenes}

RNA was extracted based on the method described by Zhang et al. [22]. The main reagent used is TRIzol (Invitrogen, Carlsbad, CA, USA), which is a new total RNA extraction reagent that can directly extract total RNA from cells or tissues. All RNAs used for following library preparation were determined to have RNA integrity numbers (RINs) of 6.5 and above.

\subsection{Library Construction and Sequencing}

RNA-seq library preparations were built based on the manufacturer's manual, and the Ribo-Zero rRNA removal kit (Bacteria, Illumina, San Diego, CA, USA) was applied to the loss of ribosomal RNA. The construction of the RNA-seq library mainly refers to the method of Zhang et al. [22]. The basic process includes RNA interruption, doublestranded cDNA synthesis, terminal repair, dA-tailing, splice, fragment sorting, digestion of dUTP-labeled double strand and PCR amplification. Libraries with different indices were multiplexed and loaded on an Illumina HiSeq equipment based on manufacturer's manual (Illumina, San Diego, CA, USA). The processing and analysis of sequences were operated by GENEWIZ. According to the procedure of Chen et al. [23], Bowtie2 (v2.2.6) was utilized to index the reference genome sequence of L. monocytogenes FSL F6-684 (https: / / www.ncbi.nlm.nih.gov/nuccore/JOOX00000000 (accessed on 1 December 2019)). All transcriptome raw data were stored at the National Center for Biotechnology Information (NCBI) Sequence Read Archive (SRA) database, registered as PRJNA756162.

\subsection{Differentially Expressed Genes Analysis}

Initially, the known gff annotation file was converted to fasta format. Then the file was used as a reference gene file, and accurate indices were made. The expression level of a gene is directly reflected by its gene abundance. The higher the gene abundance, the higher the gene expression level. Gene expression was calculated by using Htseq software (v0.6.1p1). The software uses FPKM (Expected Number of Fragments Per Kilobase of Transcript Sequence Per Millions base pairs sequenced) to calculate gene expression [24]. For samples with biological duplication, differentially expressed genes analysis was performed by using DESeq2 (v1.6.3) from the Bioconductor software package. Based on Hochberg and Benjamini's method, the results were screened according to the differential significance criteria (the differential gene expression change was more than 2 times and $p$-value (padj) $\leq 0.05$ ), and the upregulation of the differential expressed genes (DEGs) expression was counted.

\subsection{GO and KEGG Pathway Enrichment Analyses}

Gene Ontology (GO)-enrichment analysis method is GOseq (v1.34.1), which is based on Wallenius non-central hyper-geometric distribution. By estimating the bias of gene length, the probability of GO term enrichment by DEGs can be more accurately calculated. The screening criteria for significant enrichment was padj $<0.05$. Then topGO was utilized to plot Directed Acyclic Graph (DAG). Kyoto Encyclopedia of Genes and Genomes (KEGG) is a primary public database of Pathways. Pathway-significance enrichment analysis was conducted by using the KEGG pathway as a unit and using hypergeometric test to find out which pathway was significantly enriched in DEGs as compared with the whole genome background. In the study, scripts in house were utilized to enrich significant DEGs in KEGG pathways.

\subsection{Construction of Deletion Strains}

Genes obtained by transcriptome analysis were used to confirm the function of the gene on the formation of suspended aggregates. The plasmid pMAD used in this study was presented by Gang Wang, the professor of Henan University. Using L. monocytogenes 100 DNA as the template, the DNA fragments on both sides of coding DNA sequence encoded cheA and cheY (cheAY) were amplified by PCR. The PCR primers used in this experiment 
are listed in Supplementary Materials Table S1. Primers P5F, P5R, P3F and P3R were used for PCR amplification of upstream and downstream homologous arms. Then the $509 \mathrm{bp}$ upstream homologous arm and $401 \mathrm{bp}$ downstream homologous arm were obtained. The two fragments were used as templates for overlapping-extension PCR (SOE-PCR). The SOE-PCR fragments and thermosensitive plasmid pMAD were digested by EcoR I and $B g l$ II, respectively [25]. Next, the two fragments of enzyme digestion were ligated and transformed to E. coli DH5 $\alpha$ and selection on LB agar with ampicillin $(100 \mu \mathrm{g} / \mathrm{mL})$. After purification from E. coli positive strains by using Plasmid Mini Kit I D6943 (Omega Bio Tek, Norcross, GA, USA), the resulting plasmids, pMAD- $\triangle$ che $A Y$, were electroporated into L. monocytogenes competent cells and also in the in-frame $\Delta c h e A Y$ mutant with the selection performed on TSA-containing erythromycin $(3 \mu \mathrm{g} / \mathrm{mL})$. Using erythromycin as the screening condition, the L. monocytogenes strain containing pMAD- $\Delta$ cheAY plasmid was subcultured continuously to realize homologous recombination. The isogenic mutant strain with deleted cheA and cheY gene was named L. monocytogenes $\triangle$ cheAY and confirmed by DNA sequencing on both strands, using primers P5F-P3R and DE-DR, respectively.

\subsection{The Strain Growth and Motility Assay}

For L. monocytogenes wild-type or mutant strains, growth curves were assayed at $37^{\circ} \mathrm{C}$. Motility assay was carried out as del Campo et al. described, onto a plate containing TSB with $0.3 \%$ agar cultured at $28{ }^{\circ} \mathrm{C}$ [26]. After $48 \mathrm{~h}$, the bacterial colony diameter was determined with Vernier caliper.

\subsection{Determination of the Ability to Form Suspended Aggregates}

A total of $200 \mu \mathrm{L}$ of L. monocytogenes wild-type or mutant strains were cultured into a $90 \mathrm{~mm}$ plastic Petri dish with $20 \mathrm{~mL} \mathrm{10 \%} \mathrm{TSB} \mathrm{medium} \mathrm{or} \mathrm{with} 10 \mathrm{~mL} \mathrm{10 \%} \mathrm{RIS} \mathrm{and} 10 \mathrm{~mL}$ $10 \%$ TSB medium. Thereafter, the $90 \mathrm{~mm}$ plastic Petri dish was cultured at $28{ }^{\circ} \mathrm{C}$ with 60 RPM for $24 \mathrm{~h}$. Then the formation of suspended aggregates was checked, compared and photographed. The aggregation partnerships were studied semi-quantitatively, using aggregation indices [19]. Suspended aggregates were collected in a centrifuge tube, and the OD600 of the solution in the Petri dish was measured. This absorbance value was defined as ODs. Then the remaining solution in the Petri dish was transferred to the centrifuge tube containing suspended aggregates, the bacteria in the centrifuge tube were thoroughly dispersed and mixed by vortex oscillation and the OD600 was measured. The absorbance value was defined as ODt. The aggregation indices were calculated according to the following formula:

$$
\% \text { aggregation indices }=[(\mathrm{ODt}-\mathrm{ODs}) / \mathrm{ODt}] \times 100 \text {. }
$$

\subsection{Statistical Analysis}

Three replicate trials were carried out for each sample, and all samples were repeated three times for the assay of suspended aggregate formation, the growth and motility assay of L. monocytogenes wild-type or mutant strains. Except for other explanations in the experiment, the data are generally expressed as mean \pm standard error (SE). Student's $t$-test was utilized to compared the mean value. The $p$-values $<0.05$ were identified as a significant difference.

\section{Results}

\subsection{Preparation and Scanning Electron Microscopic Observation of Suspended Aggregates}

Our previous research indicated that $R$. insidiosa induced suspended aggregate formation of L. monocytogenes under nutrient-poor environments (10\% TSB) at low speed [16]. Then $10 \%$ RIS was used instead of $R$. insidiosa to carry out the experiment. L. monocytogenes did not form suspended aggregates after culturing at low speed (60 RPM) for $72 \mathrm{~h}$ (Figure 1). However, in the presence of $10 \%$ RIS, L. monocytogenes formed suspended aggregates after low-speed culture for $24 \mathrm{~h}$ (Figure 1). The suspended aggregates in the broth 
were scattered and small in volume. After $72 \mathrm{~h}$ of continuous cultivation, the suspended aggregates gradually disappeared, and the suspended aggregates reached the maximum volume at $24 \mathrm{~h}$ of cultivation. This is a new observation and the first demonstration that aggregation can be induced by cell-free supernatants.

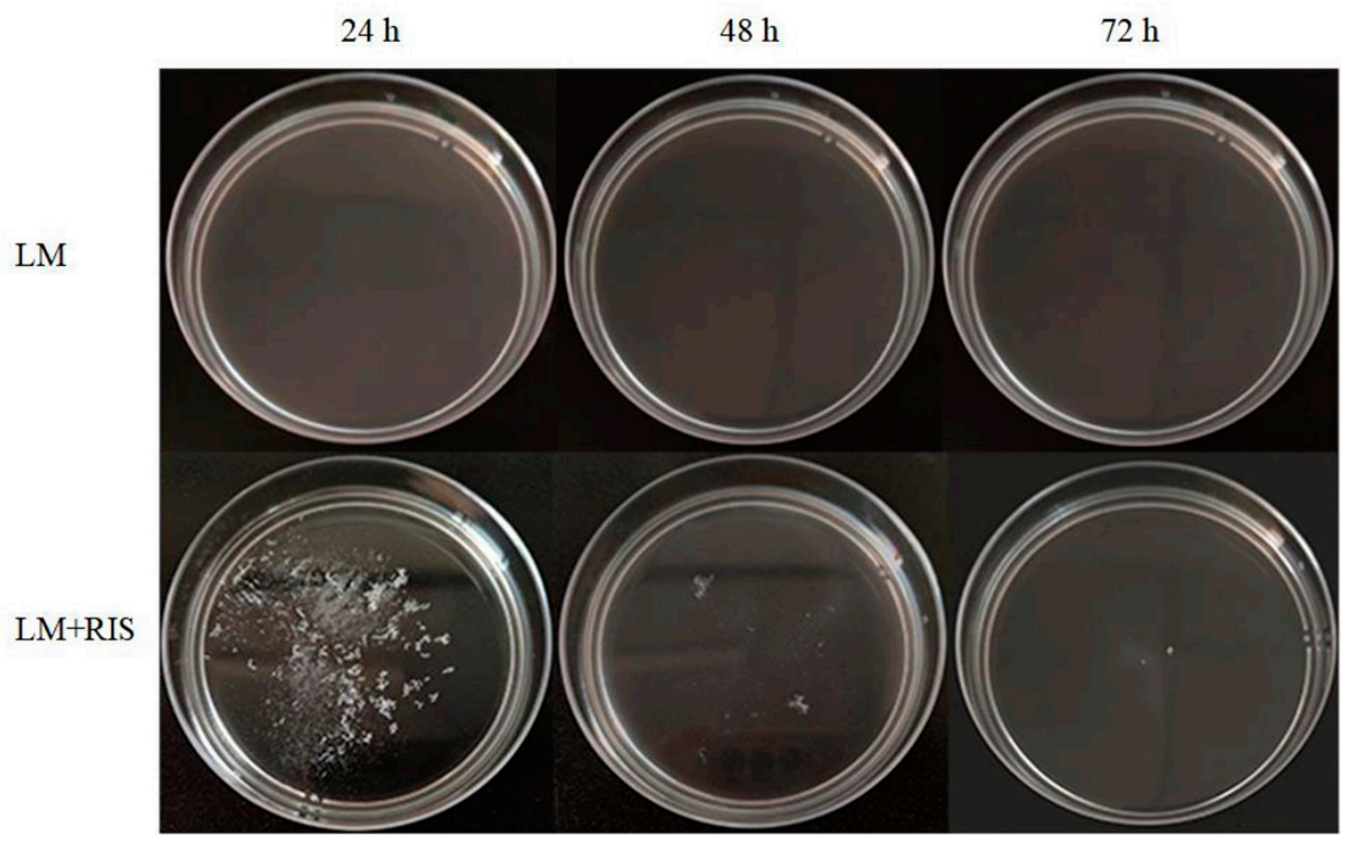

Figure 1. Suspended aggregates formed by L. monocytogenes alone or L. monocytogenes with the presence of Ralstonia insidiosa cell-free supernatants cultured in 10\% TSB medium (10\% RIS) in 10\% TSB at $28^{\circ} \mathrm{C}$ for $72 \mathrm{~h}$.

The suspended aggregates were fixed with phosphate buffer solutions of $2.5 \%(\mathrm{vol} / \mathrm{vol})$ glutaraldehyde ( $\mathrm{pH} 7.4,0.02 \mathrm{M})$. Scanning electron microscopy was used to observe the change of bacterial surface morphology. The surface of L. monocytogenes cells without the role of 10\% RIS was almost all smooth and distributed evenly (Figure 2a). After 10\% RIS treatment, L. monocytogenes aggregated into clusters with EPS (arrow) connections between the cells (Figure 2b).
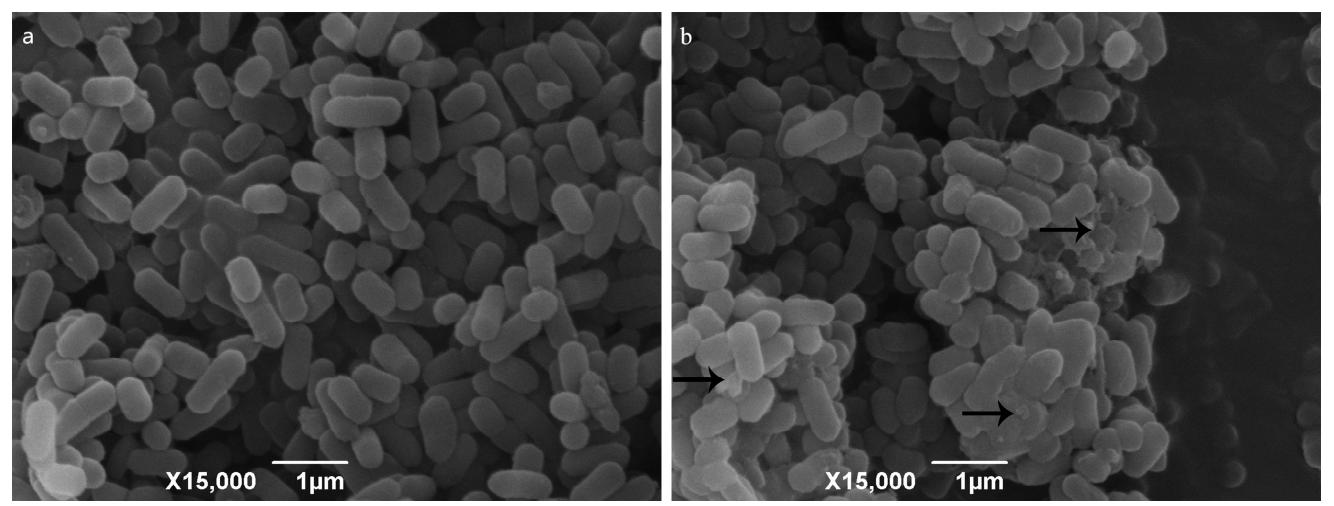

Figure 2. Scanning electron microscope images of 10\% RIS treatment. Note: (a) L. monocytogenes in $10 \%$ TSB; (b) L. monocytogenes with the presence of 10\% RIS in 10\% TSB. Arrows point to presence of EPS produced by L. monocytogenes.

\subsection{Quality Control of Sequencing Data}

To mine the transcriptome of L. monocytogenes growing in suspended aggregates or in floating state, we collected the samples under both conditions after the strain formed 
suspended aggregates or showed a floating state in plastic Petri dishes. Each sample was collected three times, which was suitable for constructing six cDNA libraries. The Illumina HiSeq platform was then used to perform RNA-seq on each library, resulting in 227.99 million reads. Then the raw data were preprocessed, and the low-quality data were filtered to remove contamination and joint sequences. The sequenced Clean Data after filtration reached 226.42 million (Q30 > 94.90\%). This indicated that RNA-seq has preferable quantity and quality, and this is conducive to comparative analysis with the reference genome of L. monocytogenes. Finally, the ratio of reads mapping to L. monocytogenes reference genome ranged from $96.54 \%$ to $99.61 \%$, showing a good mapping rate (Table 1 ).

Table 1. Data-quality statistics and reference sequence matching after filtering.

\begin{tabular}{|c|c|c|c|c|c|c|}
\hline Sample & Total Reads & Bases & $\mathrm{Q}^{2} 0^{1}(\%)$ & $\mathrm{Q}^{2} 0^{2}(\%)$ & $\mathrm{GC}^{3}(\%)$ & Total Mapped \\
\hline $\mathrm{X} 1$ & $36,894,698$ & $5,449,467,565$ & 98.08 & 94.94 & 40.97 & $36,593,927$ (99.1848\%) \\
\hline $\mathrm{X} 2$ & $34,176,440$ & $5,052,294,588$ & 98.08 & 94.90 & 41.42 & $32,993,382(96.5384 \%)$ \\
\hline X3 & $50,401,832$ & $7,445,052,570$ & 98.08 & 94.90 & 41.45 & $49,339,378(97.8920 \%)$ \\
\hline Y1 & $34,084,702$ & $5,025,917,805$ & 98.39 & 95.66 & 40.64 & $33,952,917$ (99.6134\%) \\
\hline $\mathrm{Y} 2$ & $34,081,134$ & $5,024,626,651$ & 98.46 & 95.81 & 40.79 & $33,850,013(99.3219 \%)$ \\
\hline Y3 & $36,777,634$ & $5,430,302,095$ & 98.41 & 95.72 & 40.84 & $36,502,258(99.2512 \%)$ \\
\hline
\end{tabular}

${ }^{1}$ Proportion of the total number of bases with the Phred value greater than $20 .{ }^{2}$ Proportion of the total number of bases with the Phred value greater than $30 .{ }^{3}$ Proportion of bases G and C in the total number of bases. X1-3: Non-aggregated L. monocytogenes samples. Y1-3: Suspended aggregate samples of L. monocytogenes.

\subsection{Analysis of DEGs}

According to the specifically mapped reads, FPKM values were calculated for the evaluation of relative gene expression levels in L. monocytogenes as suspended aggregates and floating cells. DESeq2 software was utilized to explore the difference of gene expression, and the DEGs were screened based on the condition (Corrected significance value of statistical difference: padj < 0.05, expression difference multiple: $\mid \log _{2}$ FoldChange $\mid>1$ ), (Supplementary Materials Table S2) [27]. Thereafter, some genes were judged to be DEGs in $10 \%$-RIS-treated samples by taking floating cells as the control. Taking group $\mathrm{X}$ as the control, we see that there were some significant DEGs in group Y, including 210 upregulated genes and 240 downregulated genes (Supplementary Materials Figure S1).

\subsection{GO Enrichment Analysis of DEGs}

GO includes three ontologies, which describe the cellular component (CC), biological process (BP) and molecular function (MF) of the gene, respectively. GO functional significance enrichment analysis showed which biological functions were significantly associated with DEGs; 30 GO terms with the most obvious enrichment of DEGs were selected. There were five types of CC: ribosome (GO: 0005840), chromosome (GO: 0005694), cell (GO:0005623), DNA topoisomerase complex (ATP-hydrolyzing) (GO: 0009330) and nucleoid (GO: 0009295). Moreover, there were 15 types of BP, the top two of which were translation (GO: 0006412) and glycolytic process (GO: 0006096), of which chemotaxis and bacterial-type flagellum-dependent cell motility terms indicate that suspended aggregate formation was closely related to bacterial chemotaxis and flagellar assembly. There were 10 types of MF; the top two terms were DNA binding (GO: 0003677) and structural constituent of ribosome (GO: 0003735) (Figure 3). 


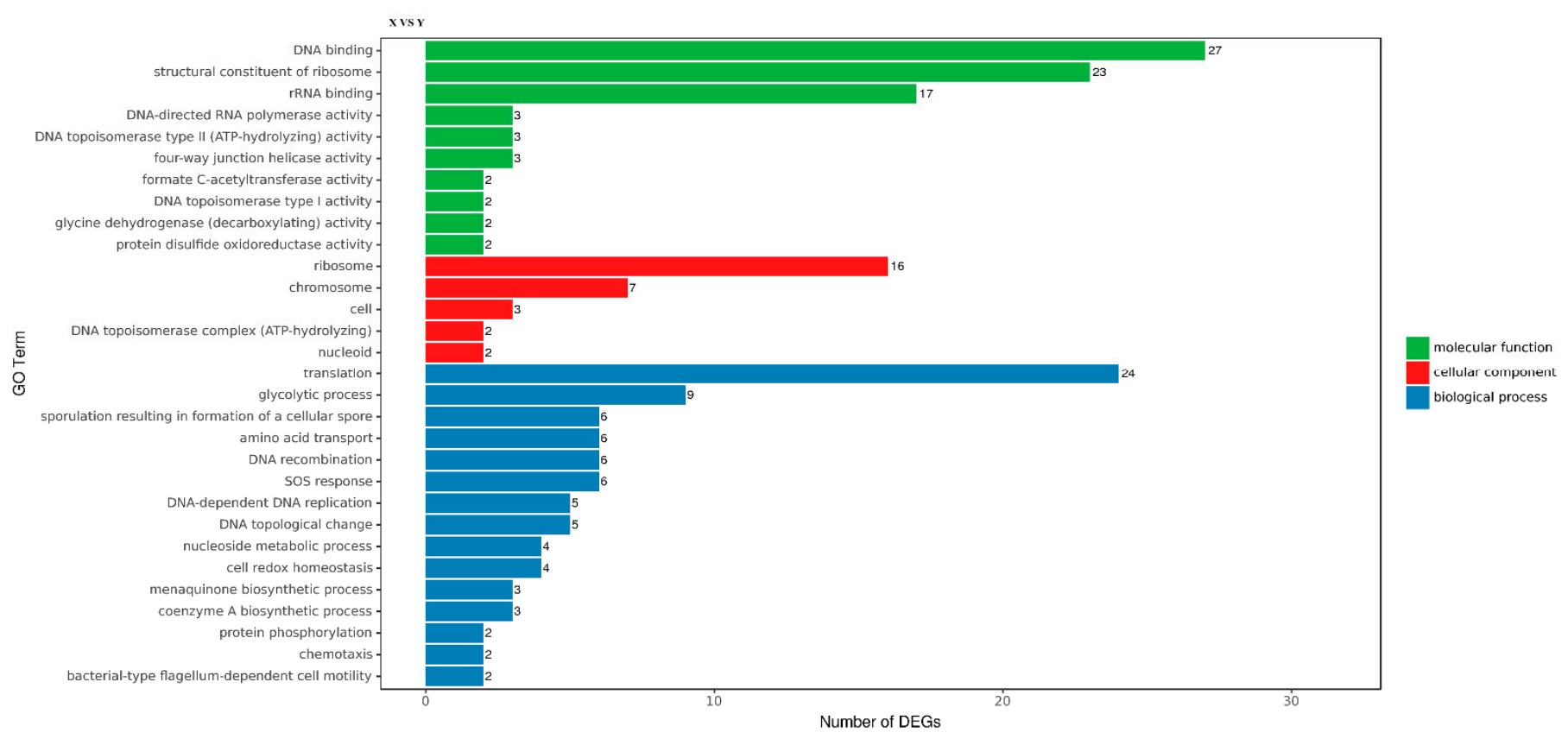

Figure 3. Gene Ontology (GO) distribution map of differentially expressed genes (DEGs) in three main categories. The $y$-axis was the GO term, and the $x$-axis was the number of DEGs in the term. Different colors were utilized to distinguish biological processes, cellular components and molecular functions.

\subsection{KEGG Enrichment Analysis of DEGs}

Figure 4 showed the 30 most significantly enriched (the lowest Qvalue) pathways. The results of KEGG enrichment indicated that there were $19 \mathrm{M}$ (metabolic) pathways, four HD (human disease) pathways, four GIP (genetic information processing) pathways, two OS (organismal system) pathways and one CP (cellular process) pathway. Four of the top five pathways were carbon metabolism (26 DEGs), pyrimidine metabolism (16 DEGs), purine metabolism (15 DEGs) and pyruvate metabolism (13 DEGs), indicating that 10\%RIS treatment stimulated the metabolism of L. monocytogenes. This deeply demonstrates that $L$. monocytogenes may change greatly after forming suspended aggregates. Therefore, deeper studies are required to reveal the mechanisms associated with metabolic changes. Ribosome-enriched multiple upregulated genes were in accordance with the results of GO annotation, indicating that the ribosome synthesis pathway was stimulated. In addition, bacterial chemotaxis, flagellar assembly and the two-component system are associated with bacterial motility and have been reported to be associated with bacterial biofilm formation. Further analysis of their relationship with suspended aggregate formation is required. 


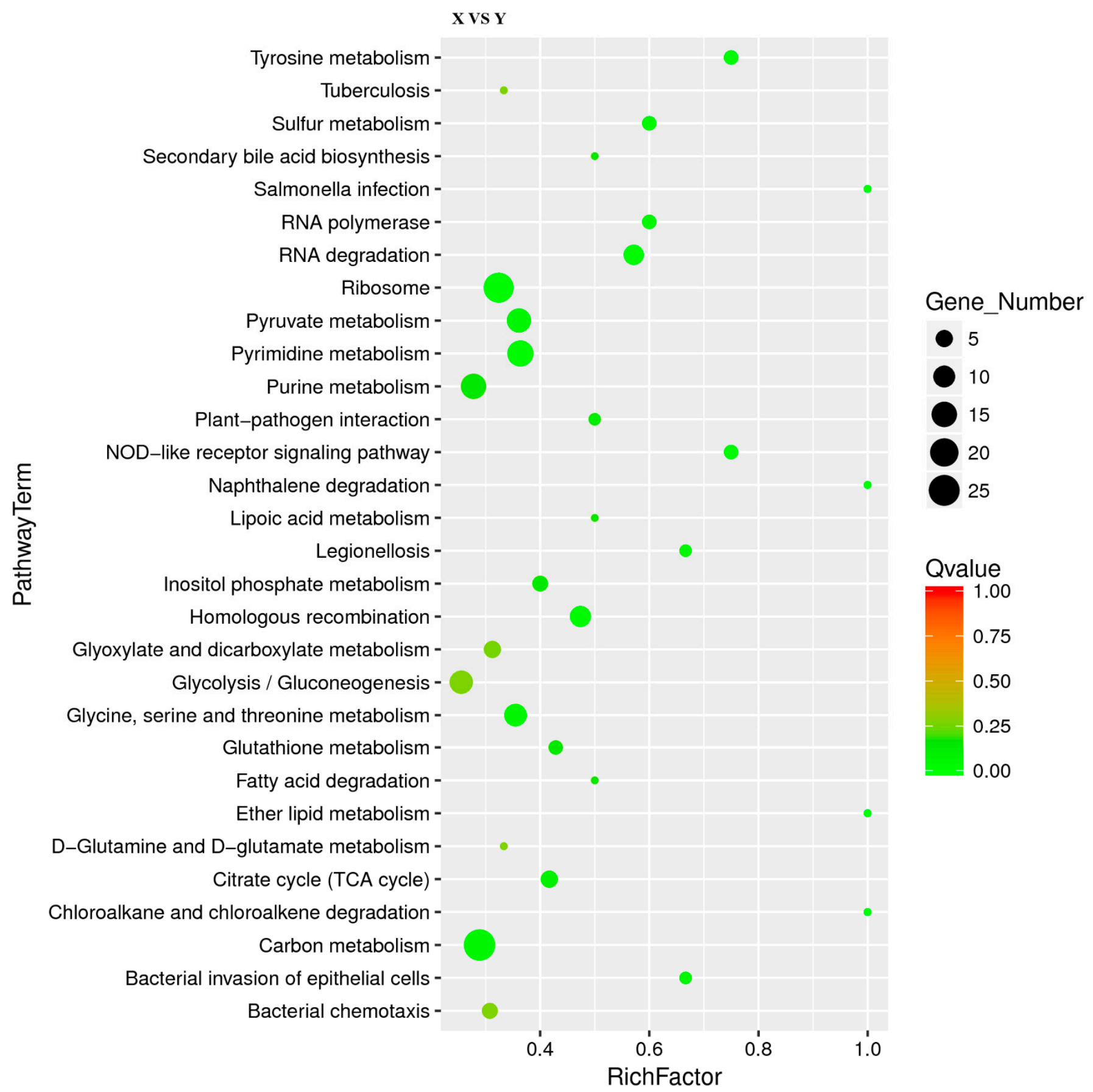

Figure 4. Scatter plot of Kyoto Encyclopedia of Genes and Genomes (KEGG) pathway enrichment for DEGs. The number of DEGs in each pathway is closely related to the size of dots, and the color of dots reflects different Qvalue values. Rich factor was positively correlated with enrichment degree. The smaller the Qvalue, the more significant the enrichment.

\subsection{Analysis of Essential DEGs}

Suspended aggregates are regarded as non-classical biofilms. Therefore, a part of gene-expression products may develop an essential impact in the formation of suspended aggregates. According to the bacterial chemotaxis, flagellar assembly and two-component system pathways, 12 DEGs associated with suspended aggregate formation were identified with the cutoff of $\mid \log _{2}$ FoldChange $\mid>1$ and padj $<0.05$ (Table 2). Seven of them play roles in the flagellar assembly pathway. Four of them play roles in the bacterial chemotaxis pathway. Nine of them play roles in the bacterial chemotaxis pathway. Some genes play a 
role in more than one pathway, and these genes also play a pivotal role in each pathway. As shown in Table 2, cheA and cheY play roles in the bacterial chemotaxis and two-component system with high upregulated expression fold change of nearly 4 and 13, respectively. Based on the gene sequence searched by NCBI, the distance between the two genes was only $20 \mathrm{bp}$, which was suitable for double gene knockout. Therefore, both genes were knocked out at the same time to verify their roles in the formation of L. monocytogenes suspended aggregates.

Table 2. Essential DEGs.

\begin{tabular}{|c|c|c|c|c|}
\hline Functional Category & Gene Name & KO_Name & Protein & $\log _{2}$ FoldChange \\
\hline $\begin{array}{c}\text { Flagellar assembly; bacterial } \\
\text { chemotaxis }\end{array}$ & DR89_RS14910 & flim & Flagellar motor switch protein FliM & 3.982754445 \\
\hline $\begin{array}{c}\text { Flagellar assembly; two-component } \\
\text { system }\end{array}$ & DR89_RS14955 & fliC & Flagellin & 1.294521613 \\
\hline Flagellar assembly & DR89_RS14880 & $f \lg K$ & Flagellar hook-associated protein FlgK & 3.199252693 \\
\hline Flagellar assembly & DR89_RS14845 & fliE & Flagellar hook-basal body complex protein FliE & 3.692945001 \\
\hline Flagellar assembly & DR89_RS15005 & flh $A$ & Flagellar biosynthesis protein FlhA & 3.37719265 \\
\hline Flagellar assembly & DR89_RS15015 & fliR & Flagellar type III secretion system protein FliR & 3.346243552 \\
\hline $\begin{array}{l}\text { Flagellar assembly; bacterial } \\
\text { chemotaxis; two-component system }\end{array}$ & DR89_RS14980 & $\operatorname{mot} A$ & Flagellar motor stator protein MotA & 3.073232587 \\
\hline $\begin{array}{l}\text { Bacterial chemotaxis; } \\
\text { two-component system }\end{array}$ & DR89_RS14945 & cheA & Chemotaxis family; sensor histidine kinase CheA & 1.975793359 \\
\hline $\begin{array}{l}\text { Bacterial chemotaxis: } \\
\text { two-component system }\end{array}$ & DR89_RS14950 & cheY & Chemotaxis family, chemotaxis protein CheY & 3.748414246 \\
\hline Two-component system & DR89_RS13310 & lias & NarL family, sensor histidine kinase LiaS & 2.473963827 \\
\hline Two-component system & DR89_RS03800 & maeA & NAD-dependent malic enzyme & 1.511261314 \\
\hline Two-component system & DR89_RS07650 & $c y d B$ & Cytochrome d ubiquinol oxidase subunit II & -2.073407712 \\
\hline Two-component system & DR89_RS16575 & frdA & Flavocytochrome c & -2.919069109 \\
\hline Two-component system & DR89_RS08575 & $\operatorname{agr} A$ & DNA-binding response regulator & -1.516198497 \\
\hline
\end{tabular}

\subsection{The Role of cheA and cheY in Strain Growth and Motility of L. monocytogenes}

The gene-deletion strain was constructed by using the homologous recombination technique and is referred to as L. monocytogenes $\triangle$ cheAY. There was no significant difference in growth rates at $37^{\circ} \mathrm{C}$ between L. monocytogenes wild type and L. monocytogenes $\Delta$ cheAY (Figure 5a). It showed that the absence of cheA and cheY would not affect the growth of L. monocytogenes. Then the motility based on chemotaxis was evaluated by quantifying the spread capacity of the strain on semisolid agar plates [28]. The colony diameters of the wild-type and mutant strains on semisolid agar plates were about $20.9 \pm 1.3 \mathrm{~mm}$ and $9.5 \pm 0.5 \mathrm{~mm}$, respectively, the motility assay could reveal there were significant difference (Figure $5 b$ ). These data indicate that the deletion of che A and cheY significantly affected the motility of L. monocytogenes. 
a

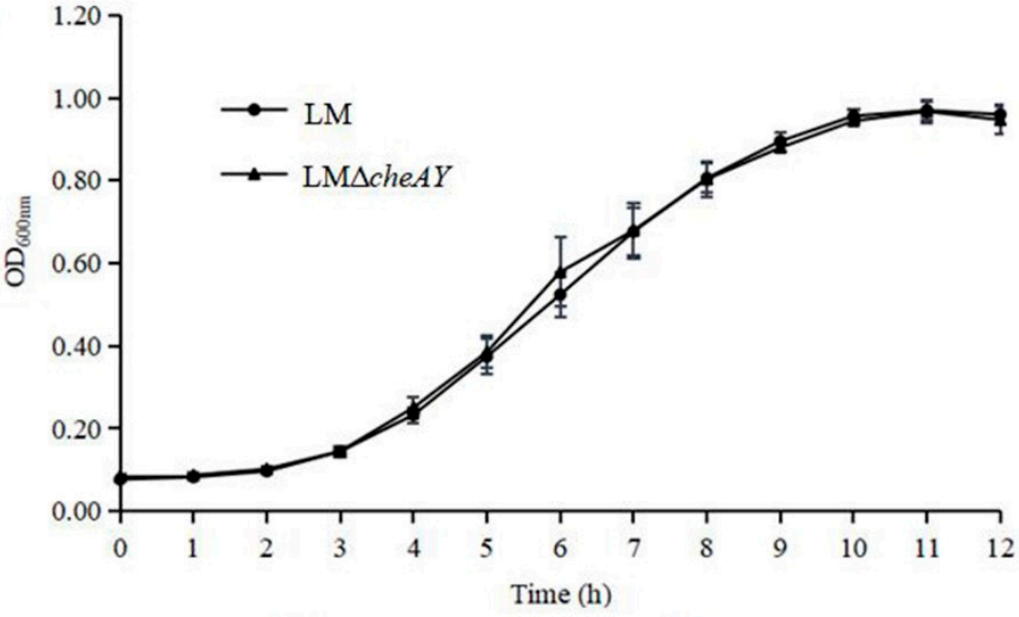

LM

$\mathrm{LM} \Delta$ cheA $Y$

b

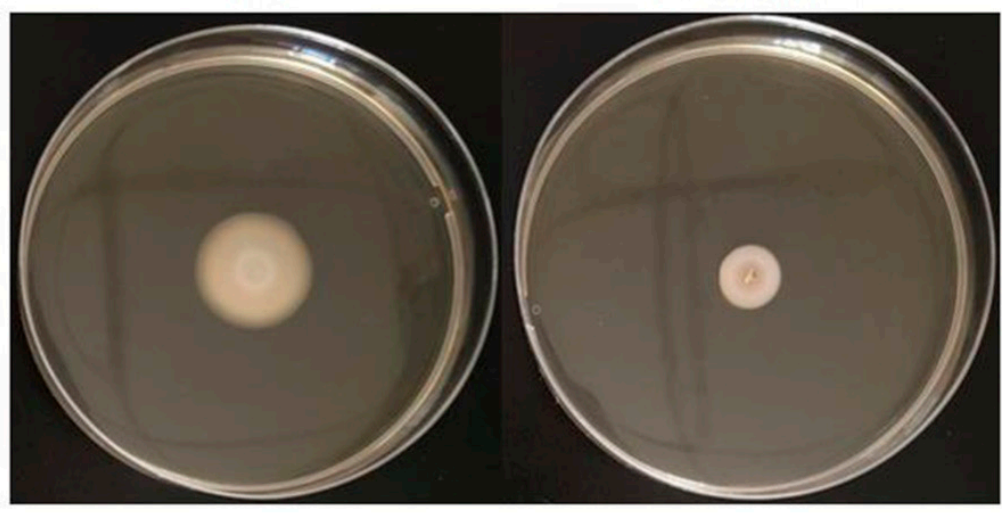

LM+RIS

LM $\Delta$ che $A Y+$ RIS

c

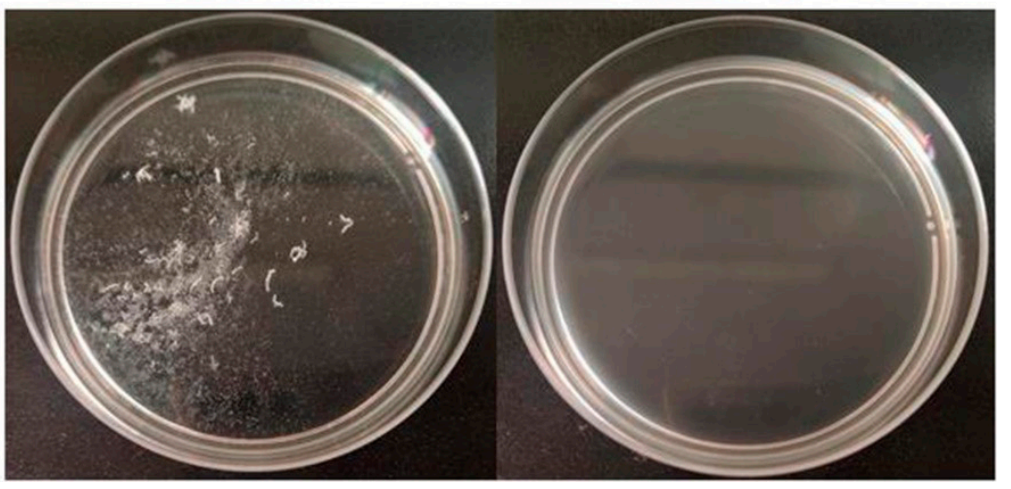

Figure 5. (a) Growth curves of L. monocytogenes and L. monocytogenes $\triangle$ cheAY at $37^{\circ} \mathrm{C}$. (b) Motility of L. monocytogenes and L. monocytogenes $\triangle$ cheAY in semisolid agar. L. monocytogenes and L. monocytogenes $\triangle$ che $A Y$ were stabbed into semisolid agar plates (TSB plus $0.3 \%$ agar). The plates were cultured at $28^{\circ} \mathrm{C}$ for $48 \mathrm{~h}$. (c) Suspended aggregates formed by L. monocytogenes and L. monocytogenes $\triangle$ che $A Y$ with the presence of $10 \%$ RIS in $10 \%$ TSB at $28^{\circ} \mathrm{C}$ for $24 \mathrm{~h}$.

\section{8. cheA and cheY are Involved in Suspended Aggregate Formation in L. monocytogenes}

Considering the essential role of che $A$ and che $Y$ in bacterial motility, we investigated the effect of cheA and cheY in suspended aggregate formation in the studied L. monocytogenes strains. With the promotion of $10 \%$ RIS, L. monocytogenes $\triangle$ cheAY could hardly form suspended aggregates compared with the wild strain, and the aggregation indices decreased from $52.92 \pm 2.29 \%$ to 0 . As a result, compared with L. monocytogenes, the ability of suspended aggregate formation of L. monocytogenes $\Delta c h e A Y$ was significantly reduced, 
even completely lost (Figure 5c). These findings support the conclusion that che $A$ and cheY play decisive roles in the formation of $L$. monocytogenes suspended aggregates.

\section{Discussion}

In our previous research, we found that $R$. insidiosa induced suspended aggregate formation of L. monocytogenes under the condition of poor nutrition at low speed [16]. Then $10 \%$ RIS was used instead of R. insidiosa to carry out the experiment. Moreover, the formation of suspended aggregates was also observed. Suspended aggregates formed by L. monocytogenes with the presence of $10 \%$ RIS was successfully characterized by aggregation indices and scanning electron microscope. This suggests that $R$. insidiosa may secrete one or more component in nutrient-poor environments that are key components in inducing L. monocytogenes to form suspended aggregates. In the actual environment, $R$. insidiosa can continuously produce key components, which continuously induce L. monocytogenes to form suspended aggregates, enhancing the resistance of L. monocytogenes to environmental conditions.

To dissect the gene related to the formation mechanism of suspended aggregates, we analyzed the transcriptome data from L. monocytogenes grown in 10\% TSB medium with the presence of $10 \%$ RIS. Starting from 6 sequenced RNA libraries, we obtained 240 upregulated DEGs and 210 downregulated DEGs. Based on the DEGs obtained, GOand KEGG-enrichment analyses were carried out to investigate the effect of $10 \%$ RIS on the formation of L. monocytogenes suspended aggregates and the potential molecular mechanism. These genes were mainly related to the two-component system, bacterial chemotaxis and flagellar assembly, which had an intense response to $10 \%$ RIS treatment. The GO-function-significance-enrichment analysis provided the GO function items that were significantly enriched in DEGs compared with the genome of planktonic cells, so as to give the biological functions that were significantly correlated with DEGs in $L$. monocytogenes under the effect of $10 \%$ RIS. According to the results of GO-enrichment analysis, it can be concluded that the presence of 10\% RIS affects the metabolic function of $L$. monocytogenes in suspended aggregates, mainly reflected in glycolysis process and amino acid transport. Through the significant enrichment of the KEGG pathway, we identified 102 biochemical metabolic pathways involved in DEGs. In the study of Fan et al., some gens related to bacterial chemotaxis and flagellar assembly were increased in biofilm cells, compared with planktonic cells [29]. Based on the current literature on biofilm formation [30,31], we mainly studied three of the 102 enriched pathways related to biofilm formation, namely bacterial chemotaxis, flagellar assembly and the two-component system.

The two-component system (TCS; ko02020) is a signal transduction system in bacteria that is involved in the regulation of most physiological processes of bacteria, including environmental adaptation, biofilm formation, bacterial chemotaxis, quorum sensing and expression of virulence genes [32]. Histidine kinase (HK) and response regulator (RR) are the main components of the TCS. They realize signal transduction through the transmission of phosphate groups. Most of HKs are transmembrane proteins, which can sense different environmental signals and are responsible for transferring extracellular signals into the cell. RR is located in the cytoplasm and is the region where phosphorylation occurs. The signal receptor domain of HK receives the signal from the external environment and phosphorylates, and then the phosphoric group is transferred to the aspartic acid residue of the regulatory domain of RR, so as to regulate the expression of downstream genes and generate the corresponding regulatory response [32]. In TCS, CheY is a response regulator consisting of a CheY-like receiver domain and a HTH DNA-binding domain DNA-binding domain, and CheA is two-component sensor histidine kinase. The autophosphorylating activity of CheA may increase by the presence of $10 \%$ RIS; then CheY was activated.

Chemotaxis is a chemotactic response produced by organisms to the stimulation of chemical substances in the external environment. The pathway is composed of histidine kinase (CheA), response modifier (CheY), methyltransferase (CheR), methyl esterase (CheB), adaptor protein (CheW) and some chemical receptors (MotA, FliM, etc.) [33]. CheA is a 
central processing unit in chemotactic pathway, sensing environmental signals through transmembrane chemoreceptors and then autophosphorylation. CheY then receives the phosphate group from CheA and binds to flagellar motor switching proteins, including FliM, FliN and FliG. This causes the flagellar to flip clockwise, causing the bacteria to move in a different direction [34]. According to the KEGG-enrichment pathway of DEGs, bacterial chemotaxis (ko02030) was significantly enhanced, and enriched with four upregulated DEGs. Similarly, cheA/cheY, which also plays a role in TCS of bacterial adaptation to selective pressure [35], was also upregulated by about 4-fold change and 13-fold change, respectively. Moreover, motA (8.42-fold change) and fliM (15.81-fold change) also showed high upregulated expression in the presence of $10 \%$ RIS.

Flagella is a special structure that widely exists on the body surface of bacteria as the result of long-term adaptation in the process of bacterial evolution. Flagellar assembly (ko02040) enables bacteria to better adapt to the environment for their own survival. As shown in Supplementary Materials Figure S2, expression levels of genes related to flagella of L. monocytogenes in suspended aggregates increased compared with L. monocytogenes in the floating state. With the inducement of $10 \%$ RIS, the expression of $f l i M$ gene encoding the bacterial flagellar motion-switching protein was upregulated by 15.81 -fold. In addition, the upregulated expression of $f l i C$ gene (2.45-fold change) was also found. FliC is a flagellar filament structural protein, which is considered to be key to motility of strains and biofilm formation [36]. MotA (8.42-fold change) and MotB proteins play the role of proton transmembrane transport in flagellar motion complex and provide the energy required for flagellar rotation. Together, they form the stator of flagella and interact with FliM, FliG and FliN proteins [37]. Other genes that are upregulated in flagellar assembly include flhA (encoding flagellar biosynthetic proteins), fliR (encoding flagellar type III secretion system proteins), flh $A$ (encoding flagellar biosynthetic proteins), flgK (encoding hook-related proteins) and fliE (encoding flagellar hook-basal body complex protein).

Based on the results discussed above, the regulatory network of suspended aggregates formed by L. monocytogenes with the presence of $10 \%$ RIS was summarized in nutrient-poor environments (Figure 6). L. monocytogenes was stimulated by one or more component in 10\% RIS when it is in nutrient-poor liquid environments. Then histidine kinase CheA, which acts on both TCS and bacterial chemotaxis, was activated and autophosphorylated. CheY then received the phosphate group from CheA to form phospho-CheY, which acts on TCS and bacterial chemotaxis pathway. Phospho-CheY binds to proteins in the flagellar motor switch complex, which consists of FliM, FliN and FliG, resulting in increased expression of flagellar assembly related genes (fliM, $\operatorname{mot} A, f l i C$, etc.). The rotation direction of flagella is affected, and the original clockwise direction is replaced by counterclockwise direction. The clockwise rotation of the flagellum makes the cell rotate in place and remain stationary, while the counterclockwise rotation makes the flagellum form a single rotating bundle and produce smooth swimming behavior [38]. Under the condition of low-speed culture, the change of rotation direction makes L. monocytogenes physically move in a certain direction and may eventually result in the formation of suspended aggregates.

To explore the possible mechanism of L. monocytogenes forming suspended aggregates with the presence of $10 \%$ RIS by RNA-seq technology, it is also necessary to remove out vital genes related to the suspended aggregate formation to prove the function of vital genes. From the previous analysis, it can be concluded that cheA and cheY are the vital genes for the formation of suspended aggregates. The distance between cheA and cheY fragments is only $20 \mathrm{bp}$. Therefore, based on homologous recombination technology, we knocked out these two genes at the same time to verify their effect on suspended aggregates.

Both cheA and cheY can directly play roles in TCS and bacterial chemotaxis pathway, which are situated in the bicistronic unit [39]. The insertion inactivation experiment of cheYA operon suggests that the colony aggregation ability of L. monocytogenes decreased [40]. In our study, the growth of L. monocytogenes $\triangle$ cheAY in TSB medium was not affected, but the movement on $0.3 \%$ agar plates was restricted, indicating that the proteins encoded by che $A$ and che $Y$ genes play a decisive role in chemotaxis. Moreover, Dons et al. also obtained 
the same experimental results [30]. In nutrient-poor liquid environments, L. monocytogenes $\triangle$ che $A Y$ can hardly be induced to form suspended aggregates by $10 \%$ RIS. The contribution of che $A$ and cheY to the suspended aggregates of $L$. monocytogenes is consistent with the study of Liu et. al, which showed that the simultaneous deletion of cheA and cheY reduced the formation of Azorhizobium caulinodans biofilms and the production of EPS [30]. The results of the determination of the ability to form suspended aggregates indicate that che $A$ and che $Y$ are the key genes regulating the formation of suspended aggregates, and explain the dependence of the aggregation of L. monocytogenes on chemotaxis. It has been documented that bacterial chemotaxis is the tendency to move to environments with higher concentrations of beneficial chemicals or lower concentrations of toxic chemicals [41]. Based on the above experimental results and the literature basis, the preliminary mechanism of the formation of L. monocytogenes suspended aggregates may be as following: under the action of $10 \%$ RIS with high concentration of specific chemical substances, the loss of chemotaxis genes makes L. monocytogenes lose chemotaxis. The scattered-chemotaxis mutants were unable to incline to the key chemicals in $10 \%$ RIS, thus failing to form suspended aggregates of L. monocytogenes.

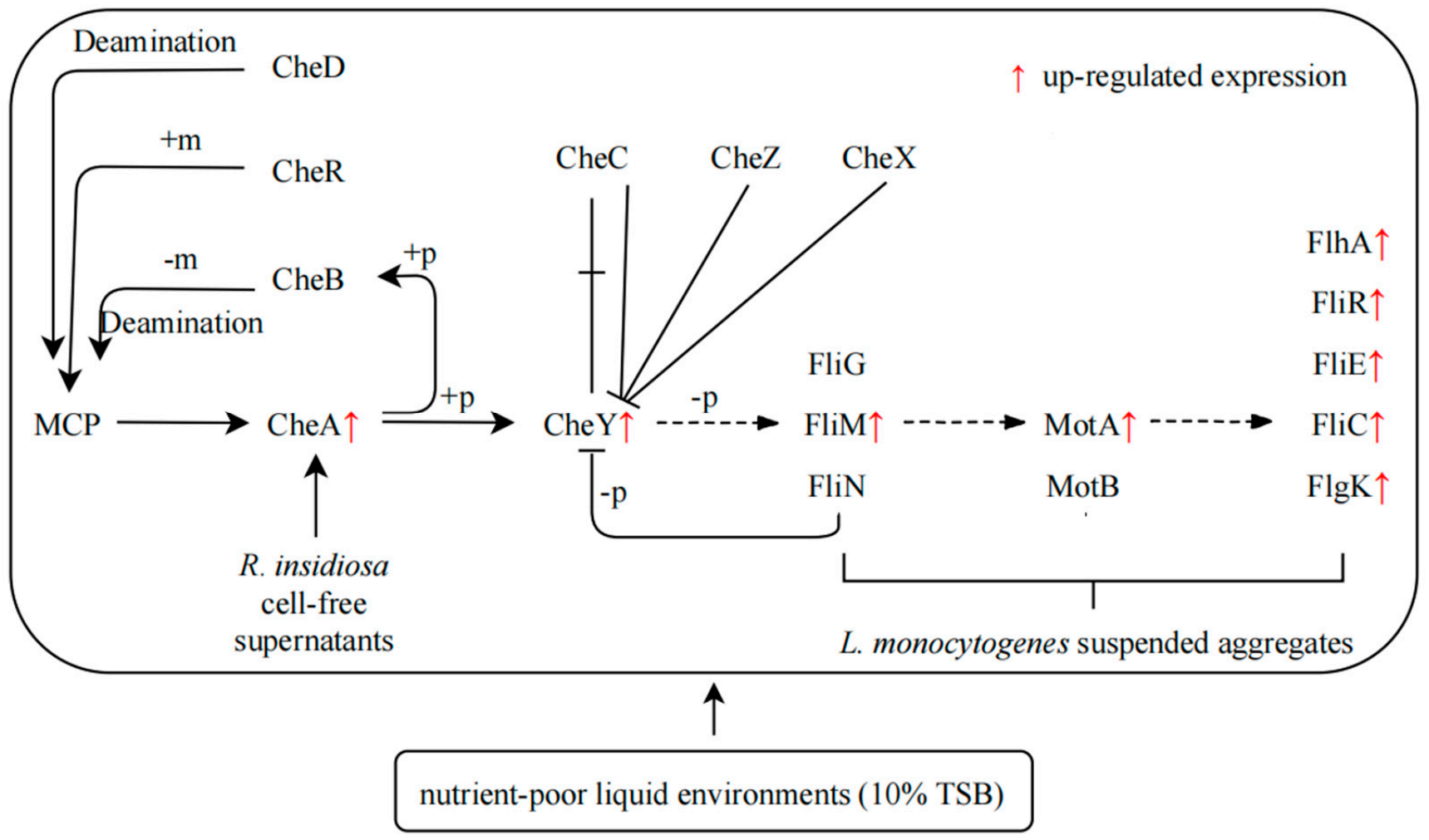

Figure 6. Formation of suspended aggregates of L. monocytogenes induced by $10 \%$ RIS Scheme 10 . TSB environments. $+\mathrm{p}$ : Phosphorylation, phosphorylation of a molecule is the attachment of a phosphoryl group. Note: $-\mathrm{p}$, dephosphorylation-as the reverse process of phosphorylation, dephosphorylation is the removal of a phosphate $\left(\mathrm{PO}_{4}{ }^{3-}\right)$ group formed by the hydrolysis of organic compounds; $+\mathrm{m}$, methylation-methylation denotes the addition of a methyl group on a substrate, or the substitution of an atom (or group) with a methyl group; $-\mathrm{m}$, demethylation-demethylation is the chemical process of removing methyl group $\left(\mathrm{CH}_{3}\right)$ from the molecule; deamination-deamination is the removal of an amino group from a molecule. Enzymes that catalyze this reaction are called deaminases.

\section{Conclusions}

In summary, the previous paper indicates that $L$. monocytogenes cannot form suspended aggregates when incubated alone [16]. However, under the action of $10 \%$ RIS, L. monocytogenes can form suspended aggregates in low-velocity liquid environments with nutrient deficiency. RNA-seq analysis showed that the expression of genes related to metabolism 
and motility of L. monocytogenes in suspended aggregates was significantly different from that in the float state. Suspended aggregates are considered to be non-classical biofilms, and the regulation of suspended aggregates by biofilm-related pathways, including two component systems, bacterial chemotaxis and flagellar assembly, was further analyzed. In addition, according to the sequencing results, some DEGs (cheA, cheY, mot $A$, fliM, etc.) may be bound up with the formation of suspended aggregates. The next experiment was to construct a mutant strain of L. monocytogenes with deletion of both cheA and cheY. It was found that these two genes were key genes for suspended aggregate formation, and their deletion prevented $L$. monocytogenes from being induced to form suspended aggregates by $10 \%$ RIS. The certain mechanism of che $A$ and che $Y$ involved in the formation of suspended aggregates remains to be studied. Reverse transcription-quantitative real-time PCR can be utilized to verify the expression of other genes related to these two genes. In addition, we can also explore the function of other key genes on the formation of suspended aggregates.

Supplementary Materials: The following are available online at https:/ / www.mdpi.com/article / 10.3390/microorganisms9122591/s1. Figure S1: Volcano map of differentially expressed genes (DEGs). The red dots of DEGs showed upregulation, and blue dots showed downregulation; the $x$-axis represented the fold change of gene expression in different samples; the $y$-axis represented the statistical significance of the difference in gene expression. Figure S2: Flagellar assembly pathway. Table S1: Primers constructed and used in this study. Table S2: 450 DEGs and functional annotations.

Author Contributions: Writing—original draft preparation and methodology, Q.L.; project administration and funding acquisition, A.G.; data curation and formal analysis, Y.M.; conceptualization, L.L. writing-review and editing, W.L. and Y.Z. (Yuan Zhong) software, Y.Z (Yawen Zhang). All authors have read and agreed to the published version of the manuscript.

Funding: This research was supported by Key Special Projects of Food Safety Key Technology R \& D in 2019 (Grant number: 2019YFC1605504).

Institutional Review Board Statement: Not applicable.

Informed Consent Statement: Not applicable.

Data Availability Statement: Not applicable.

Conflicts of Interest: The authors have no conflict of interest to declare.

\section{References}

1. Dortet, L.; Radoshevich, L.; Veiga, E.; Cossart, P. Listeria monocytogenes. In Encyclopedia of Microbiology, 4th ed.; Schmidt, T.M., Ed.; Academic Press: Oxford, UK, 2019; pp. 803-818.

2. Welshimer, H.J.; Donkervo, J. Listeria monocytogenes in nature. Appl. Microbiol. 1971, 21, 516-519. [CrossRef]

3. Lassen, S.G.; Ethelberg, S.; Bjorkman, J.T.; Jensen, T.; Sorensen, G.; Jensen, A.K.; Muller, L.; Nielsen, E.M.; Molbak, K. Two listeria outbreaks caused by smoked fish consumption-using whole-genome sequencing for outbreak investigations. Clin. Microbiol. Infect. 2016, 22, 620-624. [CrossRef]

4. Boatemaa, S.; Barney, M.; Drimie, S.; Harper, J.; Korsten, L.; Pereira, L. Awakening from the listeriosis crisis: Food safety challenges, practices and governance in the food retail sector in South Africa. Food Control 2019, 104, 333-342. [CrossRef]

5. Soon, J.M.; Brazier, A.K.M.; Wallace, C.A. Determining common contributory factors in food safety incidents-A review of global outbreaks and recalls 2008-2018. Trends Food Sci. Technol. 2020, 97, 76-87. [CrossRef]

6. Coenye, T.; Goris, J.; De Vos, P.; Vandamme, P.; LiPuma, J.J. Classification of Ralstonia pickettii-like isolates from the environment and clinical samples as Ralstonia insidiosa sp nov. Int. J. Syst. Evol. Microbiol. 2003, 53, 1075-1080. [CrossRef]

7. Ryan, M.P.; Pembroke, J.T.; Boatemaa, C.C. Genotypic and phenotypic diversity of Ralstonia pickettii and Ralstonia insidiosa isolates from clinical and environmental sources including High-purity Water. Diversity in Ralstonia pickettii. BMC Microbiol. 2011, 11, 194. [CrossRef]

8. Liu, N.T.; Bauchan, G.R.; Francoeur, C.B.; Shelton, D.R.; Lo, Y.M.; Nou, X. Ralstonia insidiosa serves as bridges in biofilm formation by foodborne pathogens Listeria monocytogenes, Salmonella enterica, and Enterohemorrhagic Escherichia coli. Food Control 2016, 65, 14-20. [CrossRef]

9. Stoodley, P.; Sauer, K.; Davies, D.G.; Costerton, J.W. Biofilms as complex differentiated communities. Annu. Rev. Microbiol. 2002, 56, 187-209. [CrossRef]

10. Ramalingam, B.; Sekar, R.; Boxall, J.B.; Biggs, C.A. Aggregation and biofilm formation of bacteria isolated from domestic drinking water. Water Sci. Technol. Water Supply 2013, 13, 1016-1023. [CrossRef] 
11. Leff, L.; Van Gray, J.B.; Marti, E.; Merbt, S.N.; Romani, A.M. Aquatic Biofilms: Ecology, Water Quality and Wastewater Treatment; Caister Academic Press: Wymondham, UK, 2016; Volume 36.

12. Grantcharova, N.; Peters, V.; Monteiro, C.; Zakikhany, K.; Romling, U. Bistable expression of CsgD in biofilm development of Salmonella enterica Serovar Typhimurium. J. Bacteriol. 2010, 192, 456-466. [CrossRef]

13. White, A.P.; Gibson, D.L.; Grassl, G.A.; Kay, W.W.; Finlay, B.B.; Vallance, B.A.; Surette, M.G. Aggregation via the red, dry, and rough morphotype is not a virulence adaptation in Salmonella enterica serovar typhimurium. Infect. Immun. 2008, 76, 1048-1058. [CrossRef]

14. Simoes, L.C.; Simoes, M.; Vieira, M.J. Biofilm interactions between distinct bacterial genera isolated from drinking water. Appl. Environ. Microbiol. 2007, 73, 6192-6200. [CrossRef]

15. Trunk, T.; Khalil, H.S.; Leo, J.C. Bacterial autoaggregation. AIMS microbiology 2018, 4, 140-164. [CrossRef]

16. Guo, A.; Xu, Y.; Mowery, J.; Nagy, A.; Bauchan, G.; Nou, X. Ralstonia insidiosa induces cell aggregation of Listeria monocytogenes. Food Control 2016, 67, 303-309. [CrossRef]

17. Rao, D.; Webb, J.S.; Kjelleberg, S. Competitive interactions in mixed-species biofilms containing the marine bacterium Pseudoalteromonas tunicata. Appl. Environ. Microbiol. 2005, 71, 1729-1736. [CrossRef]

18. Nielsen, S.M.; Norskoy-Lauritsen, N.; Bjarnsholt, T.; Meyer, R.L. Achromobacter Species Isolated from Cystic Fibrosis Patients Reveal Distinctly Different Biofilm Morphotypes. Microorganisms 2016, 4, 33. [CrossRef]

19. Toh, Y.S.; Yeoh, S.L.; Yap, I.K.S.; Teh, C.S.J.; Win, T.T.; Thong, K.L.; Chong, C.W. Role of coaggregation in the pathogenicity and prolonged colonisation of Vibrio cholerae. Med. Microbiol. Immunol. 2019, 208, 793-809. [CrossRef]

20. Wimpenny, J.; Colasanti, R. A simple cellular automaton model for coaggregation. Biofilms 2005, 1, 369-375. [CrossRef]

21. Zhong, J.; Zhao, X. Transcriptomic Analysis of Viable but Non-Culturable Escherichia coli O157:H7 Formation Induced by Low Temperature. Microorganisms 2019, 7, 634. [CrossRef] [PubMed]

22. Zhang, X.; Ruan, Y.; Liu, W.; Chen, Q.; Gu, L.; Guo, A. Transcriptome Analysis of Gene Expression in Dermacoccus abyssi HZAU 226 under Lysozyme Stress. Microorganisms 2020, 8, 707. [CrossRef] [PubMed]

23. Chen, Q.; Li, Q.; Guo, A.; Liu, L.; Gu, L.; Liu, W.; Zhang, X.; Ruan, Y. Transcriptome analysis of suspended aggregates formed by Listeria monocytogenes co-cultured with Ralstonia insidiosa. Food Control 2021, 130, 108237. [CrossRef]

24. Trapnell, C.; Williams, B.A.; Pertea, G.; Mortazavi, A.; Kwan, G.; van Baren, M.J.; Salzberg, S.L.; Wold, B.J.; Pachter, L. Transcript assembly and quantification by RNA-Seq reveals unannotated transcripts and isoform switching during cell differentiation. Nat. Biotechnol. 2010, 28, 511-515. [CrossRef]

25. Arnaud, M.; Chastanet, A.; Debarbouille, M. New vector for efficient allelic replacement in naturally nontransformable, low-GCcontent, gram-positive bacteria. Appl. Environ. Microbiol. 2004, 70, 6887-6891. [CrossRef]

26. Del Campo, A.M.; Ballado, T.; De la Mora, J.; Poggio, S.; Camarena, L.; Dreyfus, G. Chemotactic control of the two flagellar systems of Rhodobacter sphaeroides is mediated by different sets of CheY and FliM proteins. J. Bacteriol. 2007, 189, 8397-8401. [CrossRef]

27. Varet, H.; Brillet-Gueguen, L.; Coppee, J.-Y.; Dillies, M.-A. SARTools: A DESeq2-and EdgeR-Based R pipeline for comprehensive differential analysis of RNA-Seq data. PLoS ONE 2016, 11, e0157022. [CrossRef]

28. Hsu, C.-Y.; Cairns, L.; Hobley, L.; Abbott, J.; O’Byrne, C.; Stanley-Wall, N.R. Genomic Differences between Listeria monocytogenes EGDe Isolates Reveal Crucial Roles for SigB and Wall Rhamnosylation in Biofilm Formation. J. Bacteriol. 2020, 202, e00692-19. [CrossRef]

29. Yun, F.; Jiaju, Q.; Zhaoxin, L.; Zhiyang, F.; Yang, T.; Fengxia, L.; Haizhen, Z.; Chong, Z.; Xiaomei, B. Influence of different factors on biofilm formation of Listeria monocytogenes and the regulation of cheY gene. Food Res. Int. 2020, 137, 109405. [CrossRef]

30. Liu, W.; Sun, Y.; Shen, R.; Dang, X.; Liu, X.; Sui, F.; Li, Y.; Zhang, Z.; Alexandre, G.; Elmerich, C.; et al. A chemotaxis-like pathway of Azorhizobium caulinodans controls flagella-driven motility, which regulates biofilm formation, exopolysaccharide biosynthesis, and competitive nodulation. Mol. Plant. Microbe Interact. 2018, 31, 737-749. [CrossRef]

31. Du, B.; Gu, Y.; Chen, G.; Wang, G.; Liu, L. Flagellar motility mediates early-stage biofilm formation in oligotrophic aquatic environment. Ecotoxicol. Environ. Saf. 2020, 194, 110340. [CrossRef]

32. Gotoh, Y.; Eguchi, Y.; Watanabe, T.; Okamoto, S.; Doi, A.; Utsumi, R. Two-component signal transduction as potential drug targets in pathogenic bacteria. Curr. Opin. Microbiol. 2010, 13, 232-239. [CrossRef]

33. Ye, J.; Gao, M.; Zhou, Q.; Wang, H.; Xu, N.; Guo, M. The Only Chemoreceptor Encoded by che Operon Affects the Chemotactic Response of Agrobacterium to Various Chemoeffectors. Microorganisms 2021, 9, 1923. [CrossRef]

34. Welch, M.; Oosawa, K.; Aizawa, S.I.; Eisenbach, M. Phosphorylation-dependent binding of a signal molecule to the flagellar switch of bacteria. Proc. Natl. Acad. Sci. USA 1993, 90, 8787-8791. [CrossRef]

35. Dons, L.; Eriksson, E.; Jin, Y.X.; Rottenberg, M.E.; Kristensson, K.; Larsen, C.N.; Bresciani, J.; Olsen, J.E. Role of flagellin and the two-component CheA/CheY system of Listeria monocytogenes in host cell invasion and virulence. Infect. Immun. 2004, 72, 3237-3244. [CrossRef]

36. He, Y.; Xu, T.; Fossheim, L.E.; Zhang, X.-H. FliC, a flagellin protein, is essential for the growth and virulence of fish pathogen Edwardsiella tarda. PLoS ONE 2012, 7, e45070. [CrossRef]

37. Tang, H.; Braun, T.F.; Blair, D.F. Motility protein complexes in the bacterial flagellar motor. J. Mol. Biol. 1996, $261,209-221$. [CrossRef] 
38. Casey, A.; Fox, E.M.; Schmitz-Esser, S.; Coffey, A.; McAuliffe, O.; Jordan, K. Transcriptome analysis of Listeria monocytogenes exposed to biocide stress reveals a multi-system response involving cell wall synthesis, sugar uptake, and motility. Front. Microbiol. 2014, 5, 68. [CrossRef]

39. Dons, L.; Olsen, J.E.; Rasmussen, O.F. Characterization of two putative Listeria monocytogenes genes encoding polypeptides homologous to the sensor protein CheA and the response regulator CheY of chemotaxis. DNA Seq. 1994, 4, 301-311. [CrossRef]

40. Flanary, P.L.; Allen, R.D.; Dons, L.; Kathariou, S. Insertional inactivation of the Listeria monocytogenes cheYA operon abolishes response to oxygen gradients and reduces the number of flagella. Can. J. Microbiol. 1999, 45, 646-652. [CrossRef]

41. Wadhams, G.H.; Armitage, J.P. Making sense of it all: Bacterial chemotaxis. Nat. Rev. Mol. Cell Biol. 2004, 5, 1024-1037. [CrossRef] 